\title{
Modulation of North Pacific Tropical Cyclone Activity by Three Phases of ENSO
}

\author{
Hye-Mi Kim, Peter J. Webster, AND Judith A. CurRy \\ School of Earth and Atmospheric Science, Georgia Institute of Technology, Atlanta, Georgia
}

(Manuscript received 27 July 2010, in final form 28 October 2010)

\begin{abstract}
Tropical Pacific Ocean warming has been separated into two modes based on the spatial distribution of the maximum sea surface temperature (SST) anomaly: an east Pacific warming (EPW) and a central Pacific warming (CPW). When combined with east Pacific cooling (EPC), these three regimes are shown to have different impacts on tropical cyclone (TC) activity over the North Pacific by differential modulation of both local thermodynamic factors and large-scale circulation patterns. In EPW years, the genesis and the track density of TCs tend to be enhanced over the southeastern part and suppressed in the northwestern part of the western Pacific by strong westerly wind shear. The extension of the monsoon trough and the weak wind shear over the central Pacific increases the likelihood of TC activity to the east of the climatological mean TC genesis location. In CPW years, the TC activity is shifted to the west and is extended through the northwestern part of the western Pacific. The westward shifting of CPW-induced heating moves the anomalous westerly wind and monsoon trough through the northwestern part of the western Pacific and provides a more favorable condition for TC landfall. The CPW, on the other hand, produces a large suppression of TC activity in the eastern Pacific basin. In EPC years, all of the variables investigated show almost a mirror image of the EPW.
\end{abstract}

\section{Introduction}

The influence of the El Niño-Southern Oscillation (ENSO) on tropical cyclone (TC) activity in the Pacific basin has been examined by many studies. Over the western North Pacific, the phase of ENSO significantly affects the genesis, tracks, duration, and intensity of TCs (Chan 2000; Wang and Chan 2002; Camargo and Sobel 2005; Ho et al. 2004; Chen et al. 2006; Camargo et al. 2007b). In the warm phase of ENSO, the genesis frequency increases over the southeastern part of the western North Pacific and decreases over the northwestern part. The La Niña phase induces a reversed situation. The difference in the location of genesis in the different phases of ENSO has been explained in terms of large-scale ocean-atmosphere interaction associated with regional changes in sea surface temperature (SST), a vertical wind shear, an extension of the monsoon trough, and relative vorticity anomalies induced by wind anomalies in the lower troposphere (Chen et al. 1998; Chan 2000; Chia and Ropelewski 2002; Wang and Chan 2002; Wu et al. 2004; Kim et al. 2005; Camargo et al. 2007b).

Corresponding author address: Hye-Mi Kim, Georgia Institute of Technology, 311 Ferst Dr., Atlanta, GA 30332.

E-mail: hyemi.kim@eas.gatech.edu
In addition to $\mathrm{TC}$ genesis, the lifetime and intensity of TCs have also been shown to be associated with the phase of ENSO. In strong El Niño years, TCs tend to have more potential to reach their maximum potential intensity (MPI) and become generally more intense owing to their formation nearer the equator than normal years, thus allowing a longer period in the warmest SST environment (Emanuel 1988; Wang and Chan 2002; Camargo and Sobel 2005). TCs that formed farther east during El Niño are more likely to recurve toward higher latitudes before landfall and track to the east of China. In contrast, during La Niña, TCs tend to extend more westward, increasing the probability of landfall over China (Elsner and Liu 2003; Camargo et al. 2007b). Because of these clearly defined impacts of the phase of ENSO on TC activity in the western Pacific, ENSO is considered to be a strong predictor for seasonal TC forecasts (Chan et al. 1998; Chan et al. 2001; Wang and Chan 2002; Liu and Chan 2003, Lea and Saunders 2006).

ENSO influences TC activity in the eastern North Pacific as well as the western North Pacific. Recent studies, examining the relationship between ENSO and TC activity in the eastern North Pacific, have found both an increased number of intense hurricanes and a westward shift in the genesis location and track density during the warm ENSO phase (Irwin and Davis 1999; Chu 2004; 
Camargo et al. 2008). The westward shift of the genesis region tends to allow TCs to propagate farther westward into the central Pacific (Chu 2004). Also, a decrease in vertical shear over the central Pacific during El Niño years produces favorable conditions for TC propagation into the central Pacific (Chu 2004; Camargo et al. 2007a).

In summary, ENSO is one of the most important factors affecting TC activity in the western and eastern sectors of the North Pacific. However, the generality of the relationship between ENSO and TCs needs to be reexamined. Recent studies have shown that the warm phase of ENSO can be separated into two types based on the spatial distribution of the warm SST anomaly. The east Pacific warming (EPW, the traditional El Niño; e.g., Rasmusson and Carpenter 1982) event is maximized in the east Pacific, on the other hand, a central Pacific warming (CPW) is concentrated $60^{\circ}-80^{\circ}$ farther west to the central Pacific with maximum SST anomaly near the date line. This shifting of the warm SST anomaly appears to induce remote climate anomalies around the globe that are distinctly different to those produced by an EPW (Ashok et al. 2007; Ashok and Yamagata 2009; Weng et al. 2007, 2009; Kao and Yu 2009; Kim et al. 2009; Kug et al. 2009; Yeh et al. 2009). Furthermore, Kim et al. (2009) have found that the two forms of tropical Pacific Ocean warming have substantially different impacts on the frequency and tracks of North Atlantic tropical cyclones, which need to be supported by a longer time-series data (Lee et al. 2010).

A natural extension of the Kim et al. (2009) study is an investigation of the impact of the two types of Pacific warming on North Pacific TC activity. This study is prompted by noting that $\mathrm{CPW}$ events have increased during the last few decades while EPW events have declined (Kim et al. 2009; Kug et al. 2009; Yeh et al. 2009). Furthermore, previous studies have not separated ENSO type to examine the relationship to TCs. Moreover, the use of the Niño-3.4 index does not allow discrimination between CPWs and EPWs (Kim et al. 2009). Recently, Chen and Tam (2010) found that the western North Pacific TC frequency is markedly different between the two forms of Pacific warming events, specifically the TC frequency. Here, we extend the study of Chen and Tam (2010) to include the entire North Pacific. Following Kim et al. (2009), we will also examine the change of genesis frequency and track densities during an EPW and a CPW and also consider the La Niña [eastern Pacific cooling (EPC)] events, which are not examined in Chen and Tam (2010).

\section{Data and method}

TC activity is analyzed using data from the National Hurricane Center Best Track Files (HURDAT; available online at http://www.nhc.noaa.gov/pastall.shtml\#hurdat) for the eastern North Pacific and the Regional Specialized Meteorological Centre (RSMC) Tokyo-Typhoon Center for the western North Pacific (available online at http:// www.jma.go.jp/jma/jma-eng/jma-center/rsmc-hp-pub-eg/ trackarchives.html). Here, we define a TC as having a maximum surface wind $>17 \mathrm{~m} \mathrm{~s}^{-1}$. The analysis is focused on the most active part of the Northern Hemisphere TC season from July to October (JASO). Atmospheric data are from the National Centers for Environmental Prediction (NCEP)-National Center for Atmospheric Research (NCAR) reanalysis data (Kalnay et al. 1996) for the years between 1951 and 2006, which come with a spatial resolution of $2.5^{\circ} \times 2.5^{\circ}$. The SST dataset used in this study is the Extended Reconstructed Sea Surface Temperature version 2 (ERSSTv2; Smith and Reynolds 2004). All the variables, including the TC genesis frequency and track density, have been detrended to avoid the possible statistical influence of long-term trends found in previous studies (e.g., Emanuel 2005; Ho et al. 2004; Webster et al. 2005; Chan 2008). However, detrending does not change much of the main results (not shown).

The Pacific warming and cooling events are classified using detrended SST anomaly fields averaged between July and October. The SST anomaly is averaged over three regions (Fig. 1a): Niño-3.4 $\left(5^{\circ} \mathrm{N}-5^{\circ} \mathrm{S}, 170^{\circ}-120^{\circ} \mathrm{W}\right)$, Niño-3 $\left(5^{\circ} \mathrm{N}-5^{\circ} \mathrm{S}, 150^{\circ}-90^{\circ} \mathrm{W}\right)$, and Niño-4 $\left(5^{\circ} \mathrm{N}-5^{\circ} \mathrm{S}\right.$, $\left.160^{\circ} \mathrm{E}-150^{\circ} \mathrm{W}\right)$. EPW, CPW, and EPC are defined by the following: Niño-3 warming greater than one standard deviation (SD) for EPW; Niño-3 or Niño-3.4 cooler than one SD for EPC; and Niño-4 warming exceeding one SD for CPW, with Niño-3 staying below this range (Kim et al. 2009). A total of eight EPW years (1951, 1957, 1965, 1972, 1976, 1982, 1987, and 1997), five CPW years (1953, 1991, 1994, 2002, and 2004), and eight EPC years (1954, 1955, 1964, 1973, 1975, 1988, 1998, and 1999) are thus identified (Fig. 1b). Figure 2 displays the composite SST anomalies during the JASO period for EPW, CPW, and EPC events, respectively. The CPW (Fig. 2b) is confined to the central Pacific with a maximum SST anomaly near the date line while EPW (Fig. 2a) is concentrated in the east Pacific, in a similar location to the EPC maximum negative anomaly (Fig. 2c). Although the magnitude of the CPW SST anomaly is smaller than EPW, the background SST is greater than in the eastern Pacific and there is the potential for the formation of deep convection, which thus induces significant impact on the Walker circulation. For convenience, we refer the northwest WNP as region $\mathrm{A}\left(120^{\circ}-140^{\circ} \mathrm{E}, 20^{\circ}-35^{\circ} \mathrm{N}\right)$, southwest $\mathrm{WNP}$ as region $\mathrm{B}\left(110^{\circ}-140^{\circ} \mathrm{E}, 0^{\circ}-20^{\circ} \mathrm{N}\right)$, the central-eastern $\mathrm{Pa}-$ cific as region $\mathrm{C}\left(140^{\circ} \mathrm{E}-180^{\circ}, 0^{\circ}-20^{\circ} \mathrm{N}\right)$, and the eastern Pacific as region D (Fig. 2a). 
a) Nino Regions

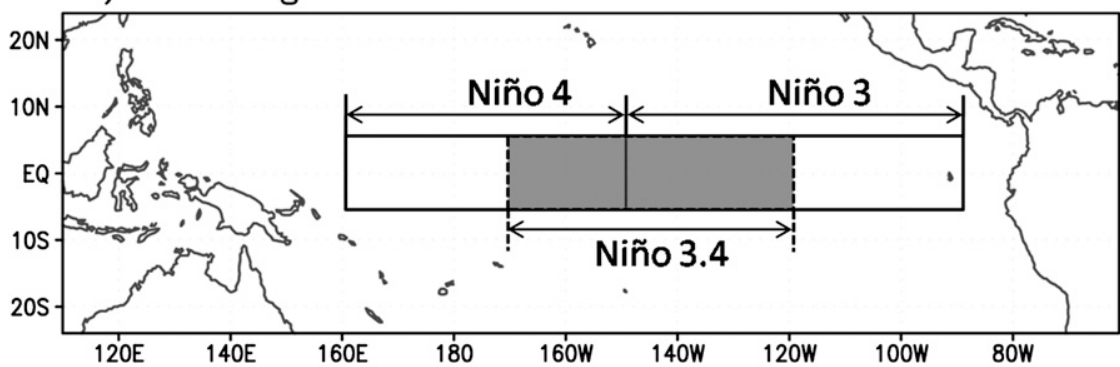

b) Normalized Nino3 (circle) and Nino4 (bar)

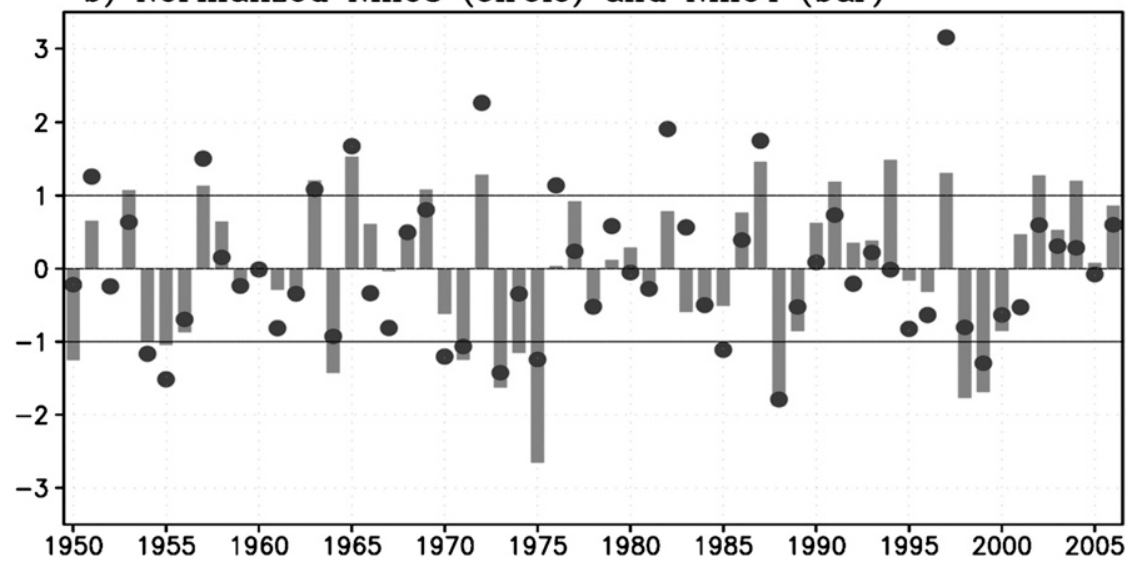

FIG. 1. (a) Location of the Niño sea surface temperature regions utilized in this study: Niño$3.4\left(5^{\circ} \mathrm{N}-5^{\circ} \mathrm{S}, 170^{\circ}-120^{\circ} \mathrm{W}\right)$, Niño-3 $\left(5^{\circ} \mathrm{N}-5^{\circ} \mathrm{S}, 150^{\circ}-90^{\circ} \mathrm{W}\right)$, and Niño-4 $\left(5^{\circ} \mathrm{N}-5^{\circ} \mathrm{S}, 160^{\circ} \mathrm{E}-\right.$ $150^{\circ} \mathrm{W}$ ). (b) Time series of normalized Niño-3 (circle) and Niño-4 (bar) index average in the 4-month period from July to October. A total of 8 EPW years $(1951,1957,1965,1972,1976$, 1982, 1987, and 1997), 5 CPW years (1953, 1991, 1994, 2002, and 2004), and 8 EPC years (1954, 1955, 1964, 1973, 1975, 1988, 1998, and 1999) were identified.

\section{Tropical cyclone activity}

\section{a. Genesis frequency}

The shifting of the maximum SST forcing changes the large-scale ocean and atmosphere circulation and thus TC characteristics over the entire North Pacific including the location of cyclogenesis and the tracks of TCs. Here, we compare the characteristics of genesis frequency by using the genesis density and the genesis potential (GP) index. Figure 3 shows the composites of mean genesis density anomalies from the 56-yr climatology. Genesis density for a specific type of warming-cooling event is defined as the number of cyclones that formed in each grid box during the JASO period divided by the total number of years during which there was an EPW, a CPW, or an EPC. Then, the genesis density is smoothed by averaging the 8 grid points surrounding the main grid point with 1:8 weighting and the total divided by 2 . The anomaly is obtained by removing the 56-yr mean for the period 19512006. The track density is calculated in a similar way to genesis density except by counting the number of cyclones moving into each box. To determine the statistical significance of track density, a bootstrap technique is applied following Kim et al. (2009). For the EPW events, a composite anomaly is constructed with $8 \mathrm{yr}$ chosen at random from among the $56 \mathrm{yr}$ of data. The process is repeated 10000 times to obtain a probability distribution at the 90\% and 95\% levels. Light and dark contours in Figs. 3-5 show statistical significance at the $90 \%$ and $95 \%$ level, respectively.

In the EPW case (Fig. 3a), positive genesis density anomalies span the central to eastern Pacific (region C), while in the EPC case, there is a decrease over the broad area in region $\mathrm{C}$. In the EPW summer, TC formation tends to be enhanced over region $\mathrm{C}$ and decreases in region $\mathrm{A}$ and region $\mathrm{B}$. These patterns are almost opposite during an EPC summer, when there is an increased risk of southeast China being subject to landfalling TCs. The eastward displacement of genesis in EPW in region $C$ has been well documented in previous studies as noted above and is generally explained by the generation of large-scale circulations that influence the extension-retreat of the 


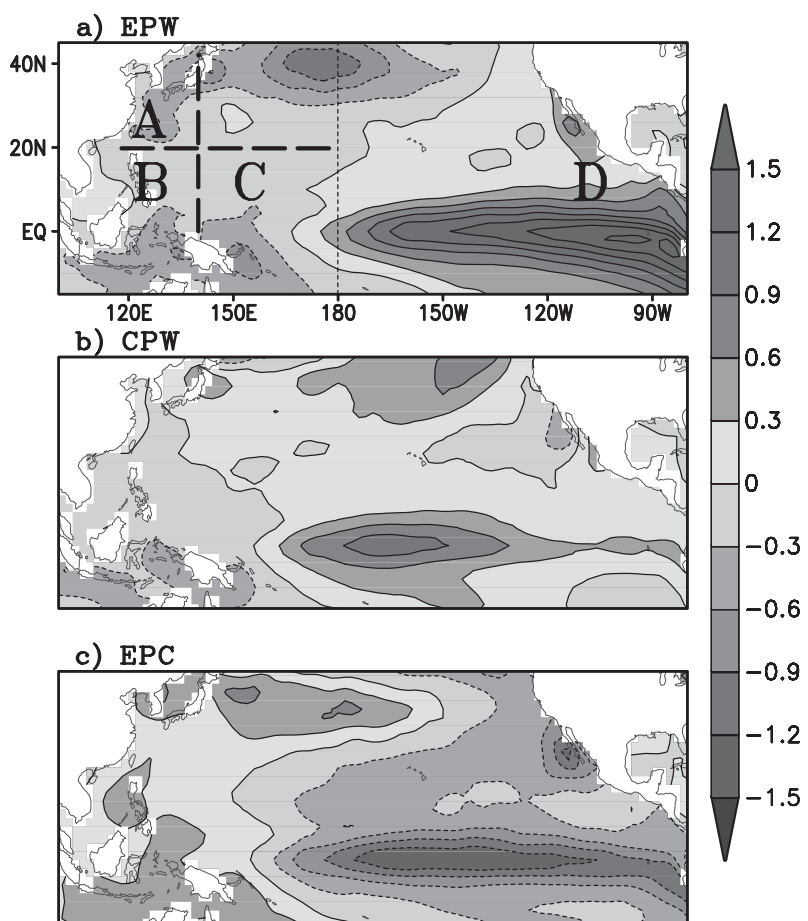

FIG. 2. Composites of SST anomalies (contours interval is $0.3^{\circ} \mathrm{C}$ ) in JASO for (a) EPW, (b) CPW, and (c) EPC years. Dashed lines indicate boundaries of subregions mentioned in the text.

monsoon trough (Chen et al. 1998), the low-level flow (Chan 2000; Wang and Chan 2002), and the vertical wind shear (Chia and Ropelewski 2002). In the CPW case (Fig. 3b), the western and eastern Pacific genesis locations are quite different from EPW. The positive genesis anomaly shifts to the west and extends through region A in a pattern very different from the EPW. The CPW TC formation over the northwestern part of the western $\mathrm{Pa}$ cific (region A) increases the probabilities of TC propagation into the northern part of East Asia, including both Korea and Japan, even though they do not appear very significant. The decrease of genesis over the southwestern part of the western Pacific (region B) may also be induced by the local thermodynamic effect caused by the negative SST anomaly (Fig. 2b) and associated subsidence. We will discuss these points in detail later. During an EPW year, the genesis frequency is increased in the $\mathrm{C}-\mathrm{D}$ region but decreases in the same region during an EPC year. The increase of TC activity during an EPW compared to an EPC over the eastern Pacific (region D) has been examined in previous studies in terms of environmental parameters affecting TC genesis (Irwin and Davis 1999; Chu 2004; Collins and Mason 2000; Camargo et al. 2007b). The TC genesis in CPW years differs from EPW in the east Pacific, especially in region D (Fig. 3b) where large cyclogenesis suppression can be found in comparison with an EPW.

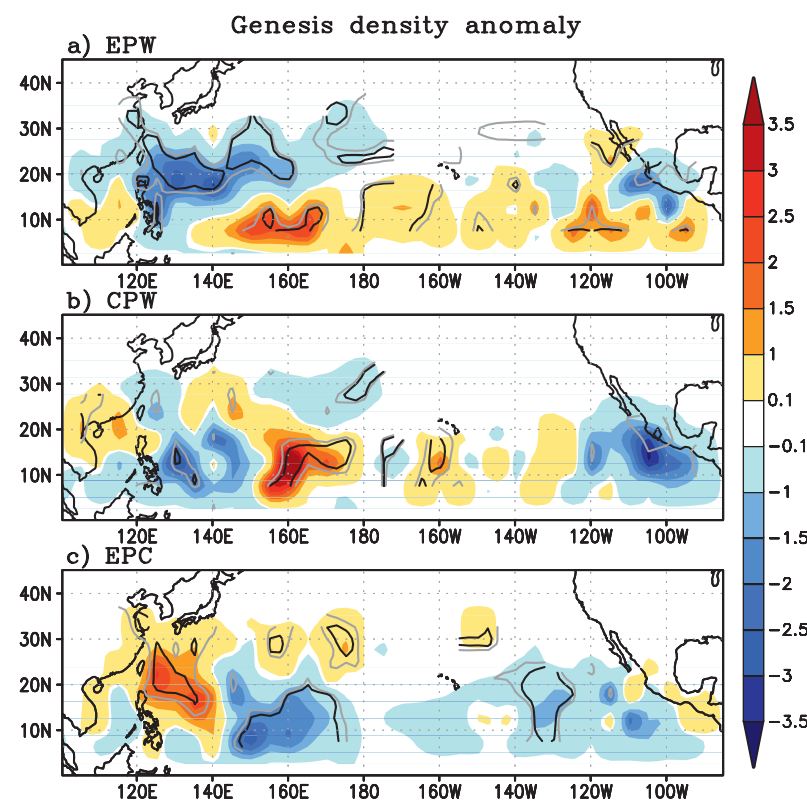

FIG. 3. Composites of genesis density anomalies $(\times 10)$ in JASO for (a) EPW, (b) CPW, and (c) EPC years. Light (dark) contours show statistical significance at the $90 \%$ (95\%) level.

Emanuel and Nolan's (2004) GP index is analyzed over the North Pacific basin to assess the combination of climate factors for TC genesis. The GP index is a combination of parameters including the absolute vorticity, relative humidity (RH), wind shear, and the potential intensity (PI;

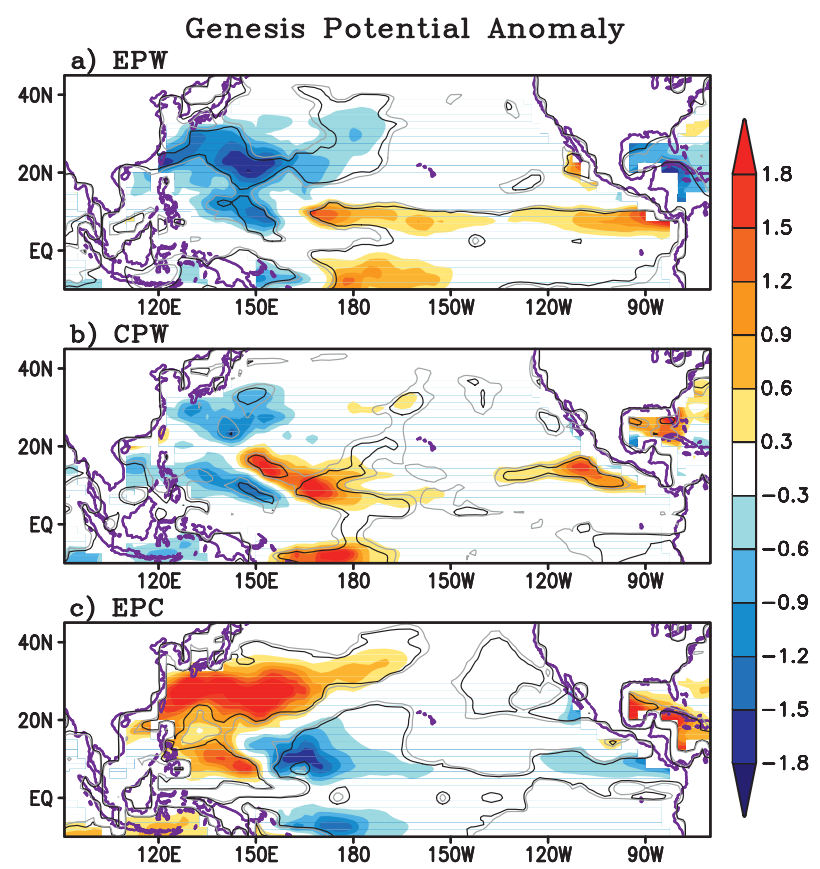

FIG. 4. As in Fig. 3, but for genesis potential anomaly. Contours are indicated only on positive values and with interval in 0.5 . 


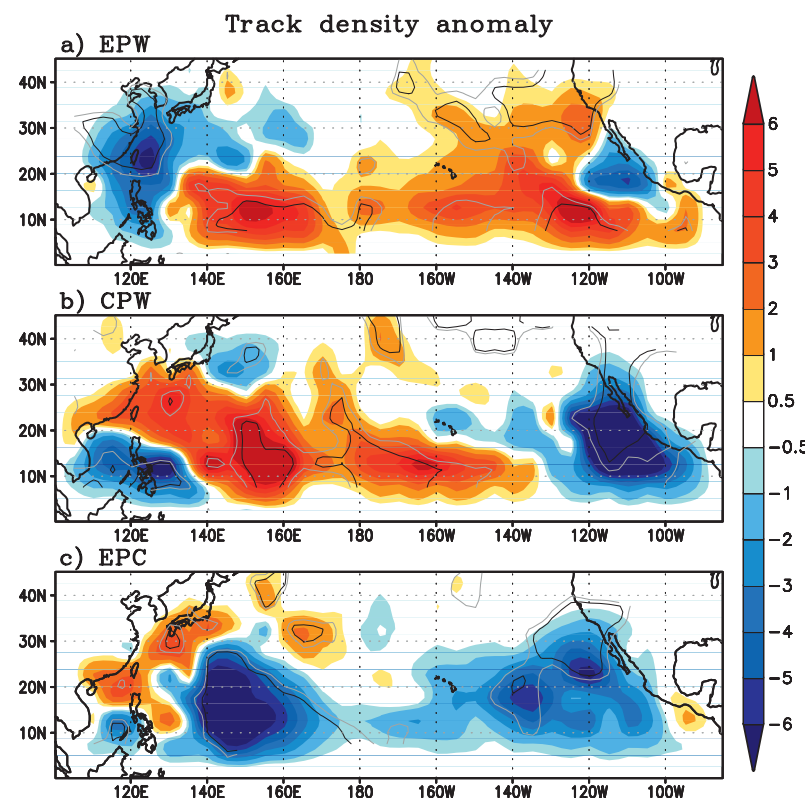

FIG. 5. As in Fig. 3, but for track density.

Emanuel 1988). The PI is obtained from the sea level pressure, SST, atmospheric temperature, and mixing ratio (Bister and Emanuel 2002). The GP index is defined as

$$
\mathrm{GP}=\left|10^{5} \eta\right|^{3 / 2}\left(\frac{H}{50}\right)^{3}\left(\frac{P I}{70}\right)^{3}\left(1+0.1 V_{\text {shear }}\right)^{-2},
$$

where $\eta$ is the absolute vorticity at $850 \mathrm{hPa}, H$ is the relative humidity at $700 \mathrm{hPa}$, and $V_{\text {shear }}$ is the vertical wind shear magnitude between 850 and $200 \mathrm{hPa}$ obtained from the 1951-2006 NCEP-NCAR reanalysis. Details of the calculation methods can be found in Emanuel and Nolan (2004) and Camargo et al. (2007a). The GP index has been shown to reproduce the variability of TC activity associated with both the annual cycle and ENSO (Camargo et al. 2007a). Figure 4 shows the composite of genesis potential anomalies in JASO for EPW, CPW, and EPC events, respectively. In an EPW year, the GP anomaly is suppressed in region $\mathrm{A}$ and $\mathrm{B}$ and enhanced in region $\mathrm{C}$ (Fig. 4a). An EPC year shows almost a mirror image of the EPW distribution (Fig. 4c). In a CPW year, the positive GP anomaly appears over the WNP with an extension to east of the date line (Fig. 4b). The positive GP anomaly over region $\mathrm{D}$ is contrary to the negative genesis density anomaly (Fig. 3b). The positive GP anomaly over region D might be due to the positive SST anomaly (Fig. 2b), positive relative humidity in the midlevel, and anomalously weak vertical wind shear (Fig. 9b). However, the descending motion over region D in CPW suppresses TC genesis. As ascending-descending motion is not considered explicitly in the GP index, the GP anomaly is in contrast to the observed genesis frequency in region D (Fig. 3b). The contribution of vertical motion on TC activity will be discussed in section 4 .

\section{b. Track density}

The difference in the cyclogenesis patterns between both types of warming events influences the propagation patterns of TCs. To examine their differences, the track density anomaly is calculated providing patterns consistent with the respective genesis density anomaly. During an EPW year (Fig. 5a), the track density is concentrated over region $\mathrm{C}$ and reduced over region $\mathrm{A}$ and $\mathrm{B}$. During an EPC (Fig. 5c), a large suppression in track density occurs over region $C$, again almost a mirror image of the EPW period. Most of the TCs in EPC years have a recurving pattern that threatens Japan, Korea, and northern China (Elsner and Liu 2003). The tracks during a CPW event (Fig. 5b) are markedly different from those occurring either in EPW or EPC events. In CPW, TCs generated over region $\mathrm{A}$ and $\mathrm{C}$ tend to penetrate through the entire western Pacific, making landfall over the eastern coast of China and the southern parts of Korea and Japan. Figure 6 shows the track density anomaly for the individual CPW years. Although 1994 seems to have a large impact on the composite analysis, the overall pattern of track density anomaly is similar to Fig. 5b even if the 1994 case is excluded in the composite analysis (not shown). Except for the 1953 case, which is similar to an EPW case, all CPW years have a similar pattern.

The TC track density over the eastern Pacific also suggests significant influences by the different forms of Pacific warming-cooling. In EPW, enhanced TC activity occurs over the central to the eastern Pacific and suppression appears near Baja California. In an EPC year, a large suppression is shown over the overall western to eastern Pacific. The CPW shows increase in the track density over the central to the western Pacific with a large suppression area over the eastern Pacific (region D), a pattern consistent in all CPW cases. The track density anomaly is reduced near Baja for EPW, CPW, and EPC cases while the mean activity there is enhanced during neutral years (not shown).

\section{Large-scale environment}

This analysis is based on the presumption that the significantly different characteristics of TC activity between EPW, CPW, and EPC can be explained by the thermodynamic and large-scale circulation factors associated with the large-scale environment. 
Track density anomaly: CPW years a) 1953
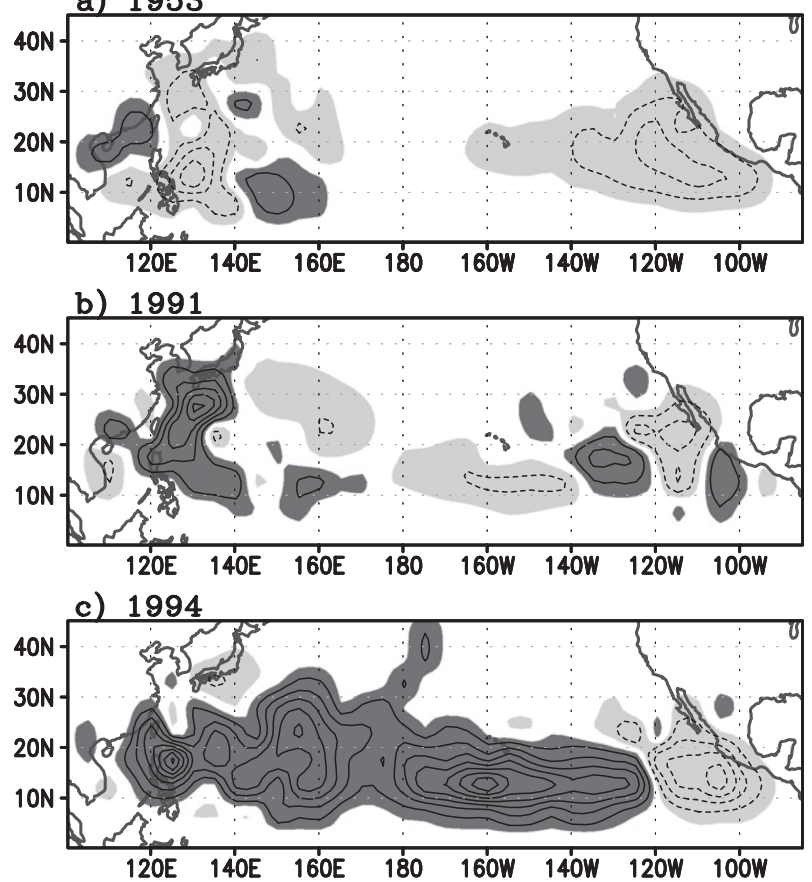

d) 2002

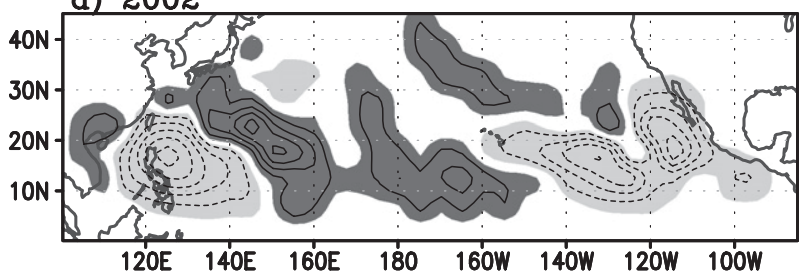

e) 2004

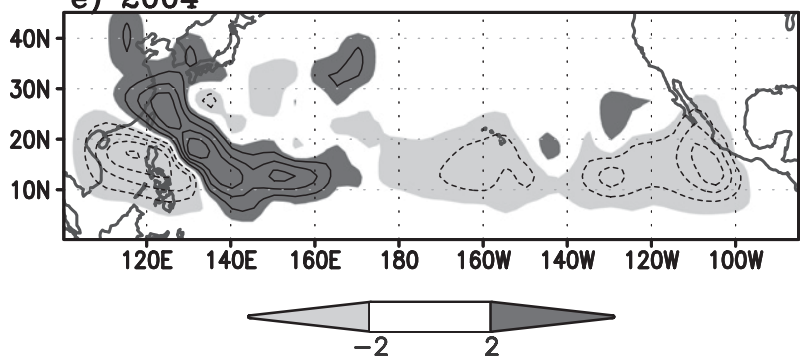

FIG. 6. Track density anomaly $(\times 10)$ in JASO for (top to bottom 5 CPW years $(1953,1991,1994,2002$, and 2004). The contour interval is 5 .

\section{a. Thermodynamic factors}

It has long been known that thermodynamic factors (e.g., SST and midlevel moisture, etc.) influence TC activity. Although deep convection has been thought to depend on SSTs of at least $28^{\circ} \mathrm{C}$ (Graham et al. 1987), most of the tropical western North Pacific region reaches $28^{\circ} \mathrm{C}$ during the Northern Hemisphere summer. Therefore, the atmospheric circulation anomaly associated with

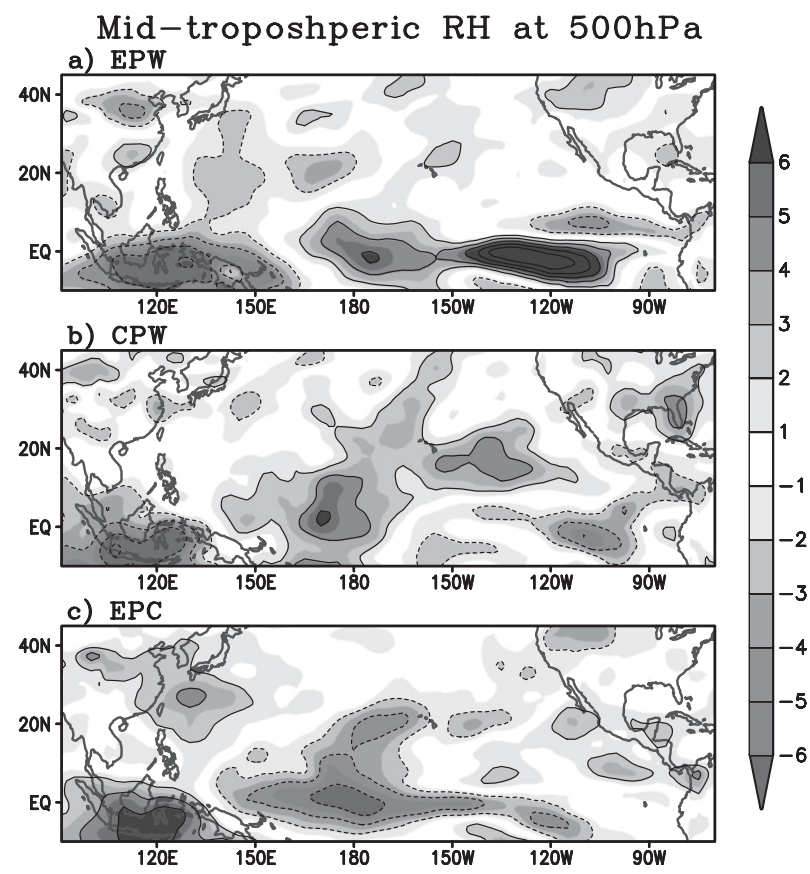

FIG. 7. As in Fig. 3, but for relative humidity anomalies (\%) at $500 \mathrm{hPa}$. The contour interval is 2 .

the boundary SST forcing plays a fundamental role in determining TC activity. The second thermodynamic factor considered in the GPI is the anomalous midtropospheric moisture (Gray 1979; Camargo et al. 2007a), whereby dry midlevels are not conducive for allowing the development of storm activity. Figure 7 shows the composite of the RH anomaly at $500 \mathrm{hPa}$ for each of three ENSO phases. The general pattern is consistent with the SST variation. In EPW (Fig. 7a), the moist air is located above the anomalous warm SST providing an opposite picture to that found with EPC (Fig. 7c). The decrease of midlevel RH near the Asian continent in EPW may lead to genesis suppression in regions $\mathrm{A}$ and $\mathrm{B}$ and also shift the genesis region to region $\mathrm{C}$ (Camargo et al. 2007b). In CPW (Fig. 7b), the positive anomaly is moved westward compared to the EPW and is consistent with the shifting pattern of underlying warm SST.

Figure 8 shows the vertical profile of $\mathrm{RH}$ for the anomalous Walker circulation associated with each ENSO phase and computed for the zonal and vertical component of the wind. Variables are averaged from the equator to $10^{\circ} \mathrm{N}$. The EPW case contains maximum moisture in the tropical midtroposphere over the central to eastern Pacific where there is anomalous ascending motion. To the west, dry descending air over the western Pacific coincides with the suppression of TC activity (Fig. 8a). However, in the CPW case (Fig. 8b), in accord with the westward shift of the maximum SST anomaly to the central Pacific, 
Anomalous Walker Circulation ( $\mathrm{RH}$ and streamline, EQ-10N)
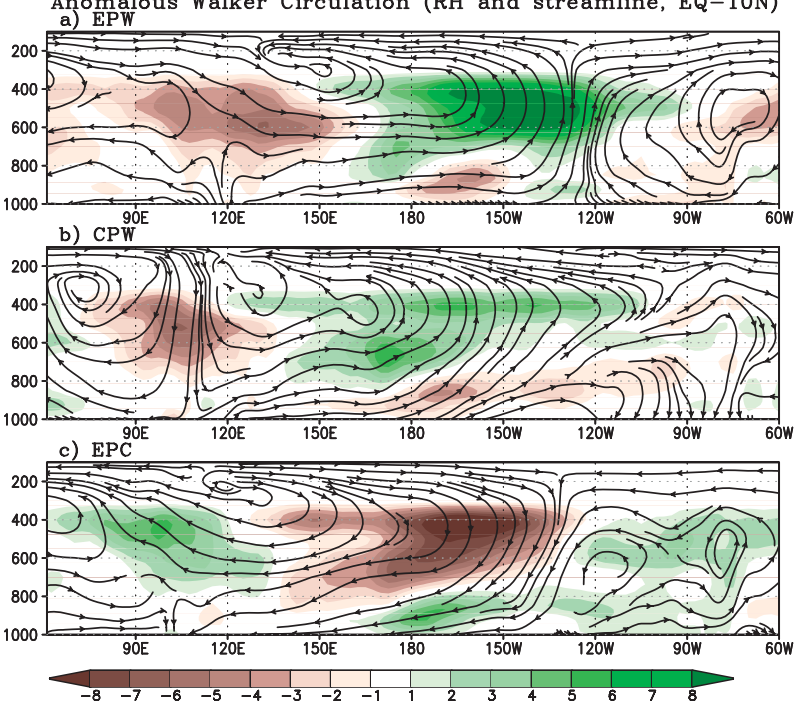

FIG. 8. Composites of relative humidity anomaly (\%, shading) and velocity anomaly (streamline) averaged from the equator to $10^{\circ} \mathrm{N}$ for (a) EPW, (b) CPW, and (c) EPC. The anomalous vertical velocity at the pressure levels has been multiplied by 50 .

anomalous ascending motion accompanied by midtropospheric moistening is also shifted to the west. The adjacent descending motion with dry air in the east Pacific induces the suppression that may inhibit the TC activity in region D. Although positive moist anomalies occur near the surface in the east Pacific, the RH throughout the midtroposphere (Fig. 8b) and the underlying SST anomaly does not appear to be sufficient to induce TC activity because of the strong subsidence. The descending motion over region $\mathrm{B}$ is also associated with reduced TC activity. The EPC circulation (Fig. 8c) is again an almost mirror image of the EPW composite; specifically, cold SST over the central-eastern Pacific suppresses convection thus confining TC activity to the northwestern part of the western Pacific, with anomalous ascent in conjunction with the moist midtroposphere.

\section{b. Atmospheric circulation}

The atmosphere over the warm SST of the Pacific tends to be sufficiently unstable to produce TCs if the atmospheric circulation is favorable (Gray 1979). Here, we describe the characteristics of the atmospheric circulation field for the different forms of Pacific warming. The EPW enhances convective heating that is associated with the anomalous low-level $(850-\mathrm{hPa})$ westerly wind anomalies over the equatorial western to central Pacific (Fig. 9a). The strong westerly anomalies are related to a positive relative vorticity anomaly that induces TC formation in region C (Gray 1979; Chan 2000; Wang and Chan 2002). The westward shifting of CPW-induced heating moves the anomalous westerly wind toward region A (Fig. 9b). In the EPC summer, the low-level wind is almost opposite that of the EPW and is unfavorable to TC formation over the western Pacific (Fig. 9c).

The interannual variation of the wind shear differentiates the TC variability between the phases of ENSO. Strong vertical wind shear inhibits the formation and development of TCs while weak vertical wind shear promotes genesis and development (Chia and Ropelewski 2002; Clark and Chu 2002; Gray 1979). Figure 9 (shading) shows the vertical wind shear magnitude for each of the three regimes. The wind shear is defined as the magnitude of the zonal wind difference between the 850 - and 200-hPa levels. An area with climatologically weak zonal wind shear in conjunction with warm SSTs produces a region of active TC formation. There are large differences in the pattern of vertical wind shear magnitude and location for each of the three regimes. For the EPW (Fig. 9a), the weak vertical shear anomaly located near the date line to the eastern Pacific favors TCs entering the central Pacific from the east Pacific (Clark and Chu 2002). Both the strong shear in the tropical west Pacific and the weak shear near the date line occurring during an EPW increase the likelihood of TC activity enhancement to the east. The strong shear over East Asia in EPW inhibits TCs that track toward region $\mathrm{A}$, whereas the weaker shear has the opposite impact. The reduction of the wind shear over the eastern North Pacific contributes to the enhancement of TC activity in region D (Camargo et al. 2007a). In an EPC event, the strong shear anomaly near the date line and eastern North Pacific inhibits TC activity, while the reduction of shear in the western Pacific causes enhancement (Fig. 9c). In CPW years, the vertical wind shear is near normal in the northwestern part of the western Pacific (region A) and in the east Pacific basin (Fig. 9b). The weak vertical shear provides a favorable condition for TC formation, allowing TC passages through the weak shear region near the east coast of China in a contrasting manner to the situation during traditional El Niño years.

It is known that TC activity over the northwestern part of the western Pacific is also governed by the zonal and meridional location of the monsoon trough (Chan et al. 1998; Chia and Ropelewski 2002). Figure 10 shows the geopotential height and wind anomaly at $850 \mathrm{hPa}$. The midlatitude atmospheric response for EPW forcing shows an anomalous low-level cyclonic circulation over the entire central midlatitude Pacific, which intensifies the eastward extension of the monsoon trough that shifts to the southeast the favorable conditions for TC development (Fig. 10a). The anomalous anticyclonic circulation over region $\mathrm{B}$ leads to the suppression of TC formation. The circulation pattern in EPC is nearly the mirror image of EPW conditions (Fig. 10c). Both the geopotential height 


\section{Veritical wind shear \& $850 \mathrm{hPa}$ wind} a) EPW

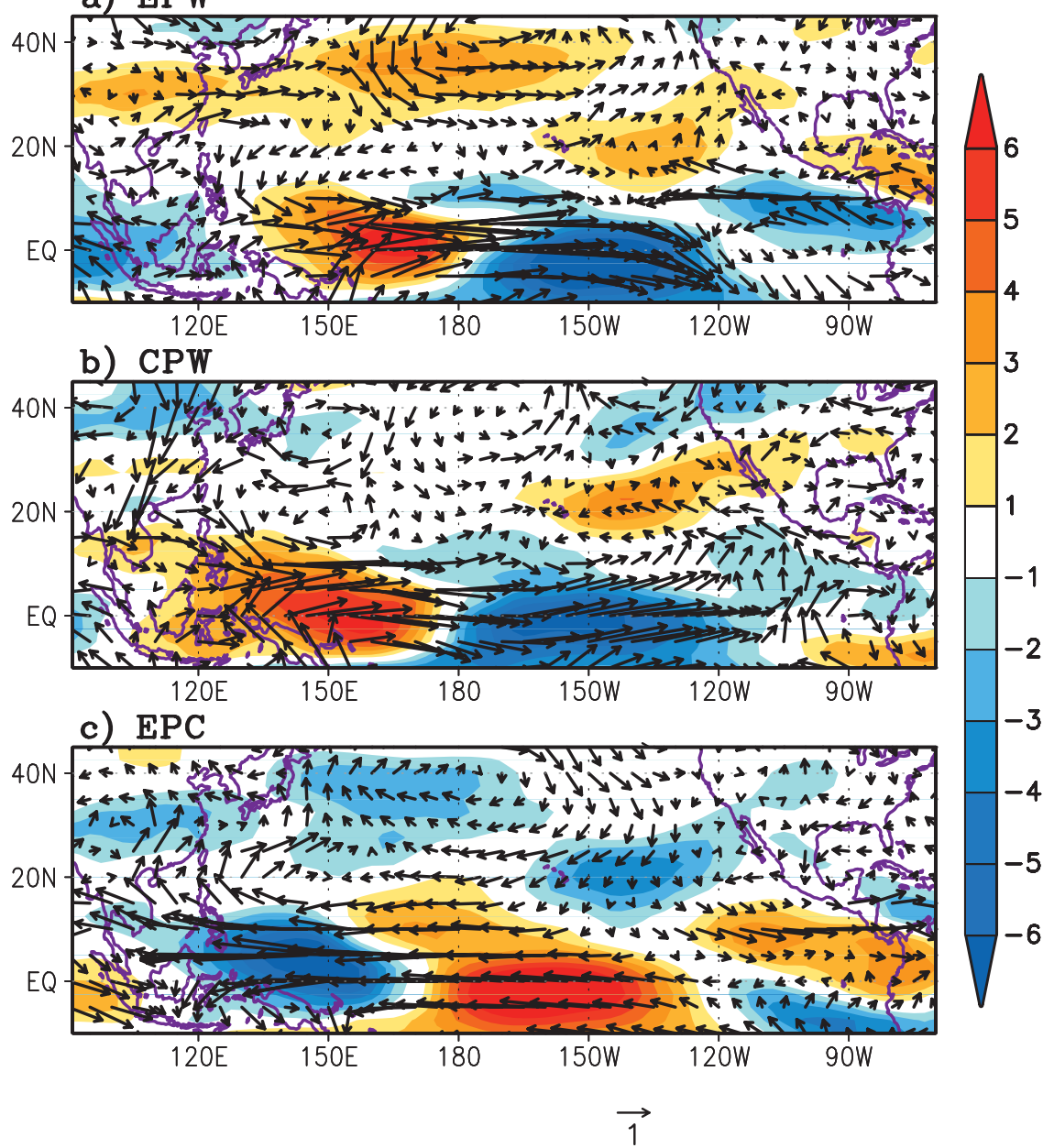

FIG. 9. Composite of vertical wind shear magnitude anomaly $\left(\mathrm{m} \mathrm{s}^{-1}\right.$, shading) and $850-\mathrm{hPa}$ wind vectors ( $\mathrm{m} \mathrm{s}^{-1}$, arrow) for (a) EPW, (b) CPW, and (c) EPC. The wind shear is defined as the magnitude of zonal wind difference between 850 and $200 \mathrm{hPa}$.

anomaly and the streamline show a westward retreated trough during the EPC summer that induces enhanced (suppressed) TC activity over region A (region C). In a CPW case, the westward shifting of the Pacific warming moves the large-scale circulation field to the west compared to EPW (Fig. 10b). The anomalous cyclonic flow over the northwestern part of the western Pacific is crucial in enhancing TC activity. The monsoon trough is deeper over the Philippine Sea and extends into region A, which enhances TC activity. The deepening of the monsoon trough in the lower troposphere also provides favorable conditions for TCs to propagate northward to the Asian continent.

\section{Summary and conclusions}

The influence of the three different regimes of ENSO on North Pacific tropical cyclone activity has been investigated by diagnosing observations in the JASO season from 1951 to 2006. The warming and cooling events are classified based on the Niño indices that depict Pacific Ocean warming or cooling. To compare the characteristics for each of these events, a composite analysis was made based on $8 \mathrm{EPW}$ years, $5 \mathrm{CPW}$ years, and 8 EPC years.

During the EPW summer, both the genesis and the track density of TCs are enhanced broadly over the central to eastern Pacific. TC formation tends to be enhanced over the central to eastern Pacific and decreased in the northwestern part of the western Pacific. In the eastern North Pacific basin, the genesis and track density is increased in EPW summer. During an EPC event, the situation is almost completely reversed. In the CPW summer, TC activity is somewhat different from EPW both in the western and eastern Pacific. The positive genesis potential index, genesis density, and track density anomaly are shifted to 


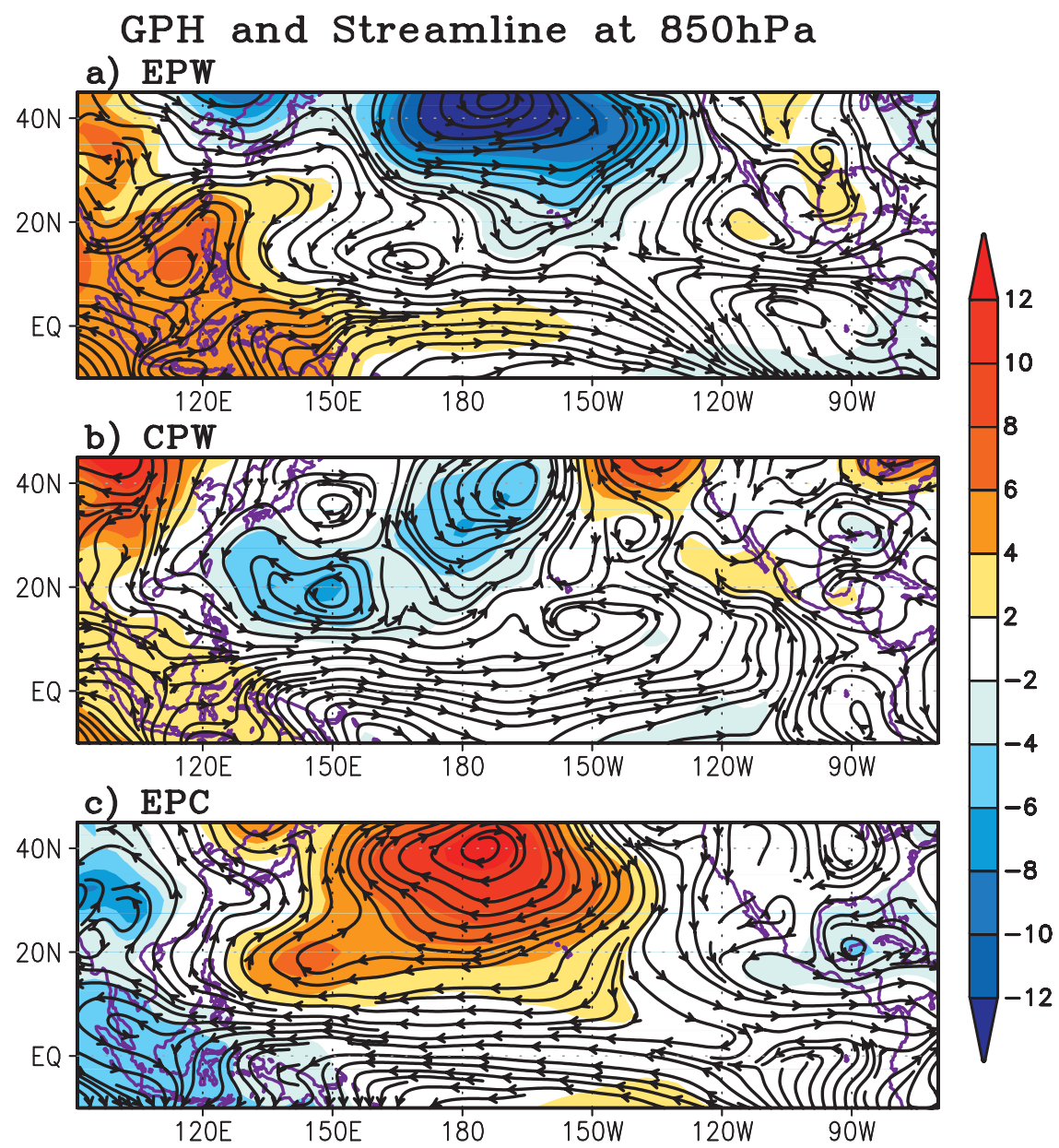

FIG. 10. Composite of geopotential height anomaly (meter, shading) and wind anomaly at $850 \mathrm{hPa}$ (streamline) for (a) EPW, (b) CPW, and (c) EPC.

the west in the western Pacific and extend through the northwestern part of the western Pacific. These patterns are distinctive from the canonical summer El Niño pattern. The TC formation over the northwestern part of the western Pacific increases the probability of East Asian landfalls, including both Korea and Japan, consistent with the recent study from Chen and Tam (2010). During CPW years, TC activities are enhanced over the central to the western Pacific with a large suppressed area over the east Pacific.

The significantly different TC characteristics between the three ENSO regimes are explained in terms of thermodynamic and large-scale circulation patterns of the large-scale environment. The TC activity anomaly shows consistency with the changes in the SST pattern over the entire North Pacific basin; the TC activity is enhanced (suppressed) as the positive (negative) SST anomaly occurs over the central to eastern Pacific in an EPW (EPC) year. In a CPW year, as the SST positive anomaly is shifted to the central Pacific, the overall TC activity pattern also seems to be shifted to the west with a broad suppressed area in the eastern Pacific. EPW events contain a high level of midtropospheric moisture over the central to eastern Pacific consistent with ascending motion. The ascending motion in the east Pacific is accompanied by anomalous descending motion with dry air over the western Pacific that suppresses TC activity. However, in the CPW case, along with the westward shift of the SST forcing, the anomalous ascending motion with midlevel moisture is also shifted to the west compared to the EPW case. The accompanying descending motion with dry air in the east Pacific induces the suppression of TC activity in eastern North Pacific.

To explain how different types of Pacific warmingcooling could affect TC activity, the variation of the atmospheric circulation is examined. During an EPW, strong westerly anomalies, related to the positive relative vorticity anomaly and extension of the monsoon trough over the 
western Pacific, induce TC formation in region C. Also, both the strong shear in the tropical western Pacific and the weak shear near the date line increase the likelihood of TC activity enhancement to the east of the climatological TC genesis location. The reduction of the wind shear over the eastern North Pacific enhances TC activity, quite opposite to what occurs during an EPC. The westward shifting of CPW-induced heating moves the anomalous westerly wind and the monsoon trough to extend through the northwestern part of the western Pacific and leads to the enhancement of TC activity over there. The deepening of the monsoon trough in the lower troposphere also provides favorable conditions for TCs to propagate into the Asian continent.

In this study, we found the influence of the three different phases of ENSO on the North Pacific TC activity. However, even though the physics to explain the CPWrelated TC activity appear solid, it is important to realize that it is a challenge to infer too much from only five CPW realizations. As mentioned in Kim et al. (2009), it is hard to know if the CPW occurrence is part of a reoccurring natural cycle such as the Pacific multidecadal oscillation, or if it may be the result of a warming world. Although we think this is a recent phenomenon, we do not know if it has occurred regularly in the past as our data record, particularly in the equatorial Pacific, is short.

As we focused on the Pacific warming event in this study, there is preliminary evidence that the central Pacific cooling events also have a different teleconnection on the globe (Cai and Cowan 2009). Future work will determine whether these differences of Pacific cooling result in changes in the characteristics of North Atlantic cyclones.

Acknowledgments. The constructive comments of two anonymous reviewers are greatly appreciated. This research has been supported in part by the Climate Dynamics Division of the National Sciences Foundation under Award NSF-ATM 0531771, NSF-ATM 0826909, NSF 0965610, and the Georgia Institute of Technology Foundation.

\section{REFERENCES}

Ashok, K., and T. Yamagata, 2009: Climate change: The El Niño with a difference. Nature, 461, 481-484.

— S. K. Behera, S. A. Rao, H. Weng, and T. Yamagata, 2007: El Niño Modoki and its possible teleconnection. J. Geophys. Res., 112, C11007, doi:10.1029/2006JC003.

Bister, M., and K. A. Emanuel, 2002: Low-frequency variability of tropical cyclone potential intensity. 1. Interannual to interdecadal variability. J. Geophys. Res., 107, 4801, doi:10.1029/ 2001JD000776.

Cai, W., and T. Cowan, 2009: La Niña Modoki impacts Australia autumn rainfall variability. Geophys. Res. Lett., 36, L12805, doi:10.1029/2009GL037885.
Camargo, S. J., and A. H. Sobel, 2005: Western North Pacific tropical cyclone intensity and ENSO. J. Climate, 18, 2996-3006.

_, K. A. Emanuel, and A. H. Sobel, 2007a: Use of a genesis potential index to diagnose ENSO effects on tropical cyclone genesis. J. Climate, 20, 4819-4834.

- A. W. Robertson, S. J. Gaffney, P. Smyth, and M. Ghil, 2007b: Cluster analysis of typhoon tracks: Part II: Large-scale circulation and ENSO. J. Climate, 20, 3654-3676.

— — - A. G. Barnston, and M. Ghil, 2008: Clustering of eastern North Pacific tropical cyclone tracks: ENSO and MJO effects. Geochem. Geophys. Geosyst., 9, Q06V05, doi:10.1029/ 2007 GC001861.

Chan, J. C. L., 2000: Tropical cyclone activity over the western North Pacific associated with El Niño and La Niña events. J. Climate, 13, 2960-2972.

- 2008: Decadal variations of intense typhoon occurrence in the western North Pacific. Proc. Roy. Soc. London, A464, 249-272.

_ J. Shi, and C. M. Lam, 1998: Seasonal forecasting of tropical cyclone activity over the western North Pacific and the South China Sea. Wea. Forecasting, 13, 997-1004.

_ J. E. Shi, and C. M. Lam, 2001: Improvements in the seasonal forecasting of tropical cyclone activity over the western North Pacific. Wea. Forecasting, 16, 491-498.

Chen, G., and C. Y. Tam, 2010: Different impacts of two kinds of Pacific Ocean warming on tropical cyclone frequency over the western North Pacific. Geophys. Res. Lett., 37, L01803, doi:10.1029/2009GL041708.

Chen, T. C., S. P. Weng, N. Yamazaki, and S. Kiehne, 1998: Interannual variation in the tropical cyclone activity over the western North Pacific. Mon. Wea. Rev., 126, 1080-1090.

_ , S. Y. Wang, and M. C. Yen, 2006: Interannual variation of tropical cyclone activity over the western North Pacific. J. Climate, 19, 5709-5720.

Chia, H. H., and C. F. Ropelewski, 2002: The interannual variability in the genesis location of tropical cyclones in the northwest Pacific. J. Climate, 15, 2934-2944.

Chu, P. S., 2004: ENSO and tropical cyclone activity. Hurricanes and Typhoons: Past, Present and Future, R. J. Murnane and K. B. Liu, Eds., Columbia University Press, 297-332.

Clark, J. D., and P. S. Chu, 2002: Interannual variation of tropical cyclone activity over the central North Pacific. J. Meteor. Soc. Japan, 80, 403-418.

Collins, J. M., and I. M. Mason, 2000: Local environment conditions related to seasonal tropical cyclone activity in the Northeast Pacific basin. Geophys. Res. Lett., 27, 3881-3884.

Elsner, J. B., and K. B. Liu, 2003: Examining the ENSO typhoon hypothesis. Climate Res., 25, 43-54.

Emanuel, K. A., 1988: The maximum intensity of hurricanes. J. Atmos. Sci., 45, 1143-1155.

_ 2005: Increasing destructiveness of tropical cyclones over the past 30 years. Nature, 436, 686-688.

— , and D. S. Nolan, 2004: Tropical cyclone activity and the global climate system. Preprints, 26th Conf. on Hurricanes and Tropical Meteorology, Miami, FL, Amer. Meteor. Soc., 10A.2.

Graham, N. E., J. Michaelson, and T. P. Barnett, 1987: An investigation of the El Niño Southern Oscillation cycle with statistical models I. Predictor field characteristics. J. Geophys. Res., 92, 14 251-14 270.

Gray, W. M., 1979: Hurricanes: Their formation, structure and likely role in the tropical circulation. Meteorology over the Tropical Oceans, D. B. Shaw, Ed., Royal Meteorological Society, 155-218. 
Ho, C. H., J. J. Baik, J. H. Kim, D. Y. Gong, and C. H. Sui, 2004 Interdecadal changes in summertime typhoon tracks. J. Climate, 17, 1767-1776.

Irwin, R. P., and R. Davis, 1999: The relationship between the Southern Oscillation index and tropical cyclone tracks in the eastern North Pacific. Geophys. Res. Lett., 26, 22512254.

Kalnay, E., and Coauthors, 1996: The NCEP/NCAR 40-Year Reanalysis Project. Bull. Amer. Meteor. Soc., 77, 437-471.

Kao, H. Y., and J. Y. Yu, 2009: Contrasting eastern Pacific and central Pacific types of ENSO. J. Climate, 22, 615-631.

Kim, H. M., P. J. Webster, and J. A. Curry, 2009: Impact of shifting patterns of Pacific Ocean warming on North Atlantic tropical cyclones. Science, 325, 77-80.

Kim, J. H., C. H. Ho, C. H. Sui, and S. K. Park, 2005: Dipole structure of interannual variation of summertime tropical cyclone activity over East Asia. J. Climate, 18, 1738-1746.

Kug, J. S., F. F. Jin, and S. I. An, 2009: Two types of El Niño events: Cold-tongue El Niño and warm-pool El Niño. J. Climate, 22, 1499-1515.

Lea, A. S., and M. A. Saunders, 2006: Seasonal prediction of typhoon activity in the Northwest Pacific basin. Preprints, 27th Conf. on Hurricanes and Tropical Meteorology, Monterey, CA, Amer. Meteor. Soc., P5.23.

Lee, S. K., C. Wang, and D. B. Enfield, 2010: On the impact of central Pacific warming events on Atlantic tropical storm activity. Geophys. Res. Lett., 37, L17702, doi:10.1029/2010GL044459.
Liu, K. S., and J. C. L. Chan, 2003: Climatological characteristics and seasonal forecasting of tropical cyclones making landfall along the South China Coast. Mon. Wea. Rev., 131,1650-1662.

Rasmusson, E. M., and T. H. Carpenter, 1982: Variations in tropical sea surface temperature and surface wind fields associated with the Southern Oscillation-El Niño. Mon. Wea. Rev., 110, 354-384.

Smith, T. M., and R. W. Reynolds, 2004: Improved extended reconstruction of SST (1854-1997). J. Climate, 17, 2466-2477.

Wang, B., and J. C. L. Chan, 2002: How strong ENSO events affect tropical storm activity over the western North Pacific. J. Climate, 15, 1643-1658.

Webster, P. J., G. J. Holland, J. A. Curry, and H.-R. Chang, 2005: Changes in tropical cyclone number, duration, and intensity in a warming environment. Science, 309, 1844-1846.

Weng, H., K. Ashok, S. K. Behera, A. S. Rao, and T. Yamagata, 2007: Impacts of recent El Niño Modoki on dry/wet conditions in the Pacific rim during boreal summer. Climate Dyn., 29, 113-129.

, S. K. Behera, and T. Yamagata, 2009: Anomalous winter climate conditions in the Pacific rim during recent El Niño Modoki and El Niño events. Climate Dyn., 32, 663-674.

Wu, M. C., W. L. Chang, and W. M. Leung, 2004: Impacts of El NiñoSouthern Oscillation events on tropical cyclone landfalling activity in the western North Pacific. J. Climate, 17, 1419-1428.

Yeh, S. W., J. S. Kug, B. Dewitte, M. H. Kwon, B. P. Kirtman, and F. F. Jin, 2009: El Niño in a changing climate. Nature, 461, $511-514$ 